\title{
La literatura en el abismo. \\ Salas Barbadillo y las colecciones de metaficciones
}

Manuel Piqueras Flores

Vigo, Editorial Academia del Hispanismo, 2018, 250 pp.

El experto en literatura española del primer tercio del siglo XVII Manuel Piqueras Flores presenta en este trabajo el fruto de su tesis doctoral -que ha sido galardonado con el Premio Internacional "Academia del Hispanismo" de Investigación Científica y Crítica sobre Literatura Española en 2017-. Piqueras nos ofrece un estudio minucioso sobre el desarrollo de un nuevo género barroco, fraguado durante la segunda década del siglo XVII, esto es, las colecciones de novelas cortas con marco que albergan cualquier tipo de ficción en su interior - ya sean obras narrativas, líricas o dramáticas-, por medio del análisis de tres obras de Alonso Jerónimo de Salas Barbadillo (1581-1635): Corrección de vicios (1615), Casa del placer honesto (1620) y Fiestas de la boda de la incasable malcasada (1622).

Este estudio se compone de tres bloques, bien diferenciados entre sí, que refieren los siguientes aspectos: "Alonso Jerónimo de Salas Barbadillo en su contexto litera- rio", "El desarrollo de un género" y "Las colecciones de metaficciones".

En el primer bloque, el autor repasa la biografía del escritor Alonso Jerónimo de Salas Barbadillo, en relación con la literatura y las influencias de las que se nutrió. Asimismo, enfatiza el hecho de que este escritor ha sido poco conocido y estudiado por la crítica hasta mediados del siglo XIX, teniendo su apogeo en los años setenta, momento en que empezaron a aflorar tesis doctorales, estudios y nuevas ediciones de sus obras. De hecho, ha sido en las últimas décadas cuando los estudios dedicados a su obra han experimentado un mayor desarrollo, ya que desde la monografía de Enrique García Santo-Tomás (2008) se han editado algunos de sus textos como $E l$ caballero puntual (Salas Barbadillo, 2016), y algunas tesis doctorales versan sobre él (Amunikan, 2012; Piqueras, 2016).

Además, Piqueras subraya el carácter innovador de Salas Barbadillo, considerado el escritor más 
innovador tras Cervantes, pues en las primeras décadas del siglo XVII tiene lugar la búsqueda de nuevos moldes, donde los textos de ficción dentro de otros textos de ficción, que difuminan los límites entre realidad y creación artística, se fraguan y para los que Piqueras propone el término de "metaficción" $y$, en consecuencia, "colecciones de metaficciones" para describir este género.

El segundo bloque es el más extenso de los tres - ya que abarca el sesenta por ciento de la obra-y en él, Piqueras analiza en profundidad los aspectos más relevantes de Corrección de vicios (1615), Casa del placer honesto (1620) y Fiestas de la boda de la incasable malcasada (1622), —obras salasianas prácticamente desconocidas hasta la fecha- y destaca un rasgo común en las tres: la posesión de un marco — si bien de distinta índole- que actúa como hilo conductor de la trama y que justifica la aparición de los episodios intercalados.

En el caso de Corrección de vicios (1615), considerada la primera colección enmarcada en literatura española, el marco es interlocutivo, y su destinataria es Ana de Zuazo. Esta obra narra el viaje autobiográfico de Salas Barbadillo con Boca de todas verdades, un loco-cuerdo, quien ameniza el viaje contando y leyendo novelas de carácter satírico, puesto que critican la sociedad áurea y el entretenimiento, y van precedidas de un diálogo entre Salas y Boca de todas verdades.

De igual manera, las ocho novelas de burlas intercaladas en esta obra, atienden al siguiente esquema: empiezan con un comentario de Boca de todas verdades, después se relata un caso real y, a continuación, se cuenta/lee una novela -aunque también se invierten los papeles y, en ocasiones, es Salas Barbadillo quien narra-. Todas las novelas comienzan con un elogio a la ciudad, narran la historia de un personaje de baja condición de la sociedad — como embusteros o malhechores - y acaban con un final moralizante y justo.

Por su parte, Casa del placer honesto (1620) sale a la luz en un año en que se publican muchas novelas de Salas Barbadillo y de colecciones que contienen novelas cortas. Esta obra es la primera colección de novelas cortas que, además de novelas cortas, incluye obras dramáticas y varios poemas, amparada bajo el marco de la reunión académica. Sus protagonistas, cuatro seńoritos andaluces, trasladan su residencia al Paseo del Prado, donde habilitan una casa en la que llevar a cabo 
cualquier tipo de representación literaria. Tras decretar una serie de normas, y crear un teatro que posibilita la inserción de géneros que no son narrativos, comienzan las representaciones. Al finalizar la primera reunión e incorporar a dos nuevos miembros, las reuniones pasan a ser periódicas, coincidiendo su celebración con la de alguna festividad religiosa. Salas Barbadillo se aprovecha de estas reuniones para otorgar al teatro y la novela el mismo grado de importancia, y para criticar a la sociedad de su tiempo.

Por otro lado, en Fiestas de la boda de la incasable malcasada (1622), Piqueras refiere, en primer lugar, la red literaria que circulaba en la época áurea, donde era habitual que unos autores escribiesen las aprobaciones de otros literatos amigos, para después examinar la obra en sí. En este libro, Salas Barbadillo presenta una comedia de equívocos, característica de la novela cortesana de tipo amorosa, que se inicia con un largo capítulo introductorio que opera como marco, y donde nos cuenta la historia de Dorotea, la "incasable malcasada" y protagonista de la trama principal. Tras las nupcias de los personajes principales, comienzan los festejos, parte fundamental de la obra, ya que conforman el grueso de esta, y justifican las ficciones en segundo grado con el fin de ridiculizar a la pareja de esposos. De esta manera, Salas Barbadillo ensalza la literatura como entretenimiento principal.

Las ficciones que componen esta obra son seis comedias domésticas y tres poemas - recitados en los intermedios-, donde una vez más, el escritor madrileño realiza una crítica a la sociedad del momento. Una crítica que deriva en el perjuicio y fracaso social de los contrayentes. Más tarde, la acción se traslada al camino de Alcalá a Guadalajara, por lo que para amenizar el trayecto los protagonistas realizan una competición poética, de modo que aquí la literatura sirve como entretenimiento y alivio de caminantes.

En el tercer y último bloque, Piqueras presenta una clasificación de las obras de Salas Barbadillo según la crítica, siendo el aspecto de "estructura" en el que encontramos mayor variedad de opiniones entre los estudiosos. Por ello, el autor hace hincapié en que las tres obras analizadas son colecciones que, mediante un marco ficcional, sirven para insertar material literario ajeno. Este hecho que no existía en la época, lo que demuestra la origi- 
nalidad de la propuesta literaria de estas obras, ya que a partir de ellas se desarrollará con éxito el género en las siguientes décadas del siglo XVII.

Más tarde, el investigador describe la diatriba entre lectura individual/privada y colectiva, siendo esta última un hábito social durante el Siglo de Oro. No obstante, en las colecciones de metaficciones, hay una primacía del leer sobre el contar, puesto que las novelas de las colecciones son casi siempre textos escritos que alguien lee a un auditorio. Además, el uso del marco pone de relieve el interés por la transmisión oral de la literatura —no solo narrativa, sino también teatral y poética - del siglo XVII. Para ejemplificarlo, Piqueras expone un dilatadísimo número de obras y de autores coetáneos a Salas Barbadillo y a las obras analizadas anteriormente, logrando así dar una visión panorámica y detallada de la situación literaria de este nuevo género barroco.

El estudioso cierra su trabajo examinando las distintas terminologías con las que los críticos han denominado a lo largo de los tiempos este tipo de obras, y proponiendo a estas colecciones que tienen novelas, obras dramáticas y poemas en distintos niveles
- como es el caso de Corrección de vicios (1615), Casa del placer honesto (1620) y Fiestas de la boda de la incasable malcasada (1622)_, que se sustentan por un marco conductor para interpolar obras literarias dentro de la ficción principal, el término de "colecciones de metaficciones".

En conclusión, este trabajo de Manuel Piqueras Flores merece un reconocimiento por su novedad, valor y riguroso estudio, ya que pone de manifiesto la necesidad de conocer a Salas Barbadillo y su vasta obra literaria. Como bien demuestra Piqueras con esta investigación, el autor madrileño fue un escritor innovador, con una prolífica carrera literaria llena de obras interesantes y de las que podemos aprender cómo se desarrolló un nuevo género literario: "las colecciones de metaficciones". El resultado del análisis de las tres obras salasianas realizado por el investigador Piqueras es brillante, y proporciona una perspectiva completa del panorama literario de la época al ponerlas en contraste con otras obras y autores. Finalmente, los comentarios y la amplia bibliografía aportada enriquecen la visión global del tema tratado, y son indispensables como punto de partida para futuros estudiosos. Asi- 
mismo, con este trabajo, Piqueras abre la veda a otras muchas líneas de investigación relacionadas con este autor, puesto que tanto Salas Barbadillo como sus textos, merecen rescatarse del olvido y proveen un extenso campo de estudio para los investigadores especialistas en la literatura del Siglo de Oro.

M. ${ }^{a}$ Dolores Marrón Guareño Universidad Autónoma de Madrid 